\title{
Apego al Lugar en Áreas Post-Desastre: el Caso de la Reocupación de la Ciudad de Chaitén, Chile
}

\section{Place Attachment in Post-Disaster Areas: The Case of the Reoccupation of Chaitén City, Chile}

\author{
Luis Maldonado y Edmundo Kronmüller \\ Pontificia Universidad Católica de Chile \\ Ignacio Gutiérrez Crocco \\ Centro de Investigación para la Gestión Integrada del Riesgo de Desastres
}

\begin{abstract}
Este estudio indaga el apego al lugar de los habitantes de la ciudad de Chaitén en Chile, una comunidad afectada por una erupción volcánica durante 2008 que destruyó gran parte de la localidad. Se pregunta por las asociaciones del apego al lugar con la vivencia directa del desastre y con la confianza interpersonal. Para responder esta pregunta, se diseñó una encuesta que contuvo instrumentos que miden apego al lugar, residencia y confianza interpersonal. Para esta última, el instrumento midió confianza en antiguos y nuevos habitantes. La encuesta fue aplicada durante 2015 a 188 habitantes de Chaitén que fueron seleccionados a partir de una muestra estratificada por sector (norte y sur de Chaitén) y bietápica. En base a regresiones lineales, los resultados indican que la experiencia directa del desastre aumenta el apego al lugar y modera levemente la asociación entre este y la confianza interpersonal en la comunidad. Confiar en antiguos habitantes aumenta el apego al lugar solo para las personas que no vivieron la erupción. No se encontró asociación entre confianza en nuevos habitantes y apego al lugar. La investigación contribuye al conocimiento del apego al lugar, sugiriéndose que un desastre tiene consecuencias positivas de largo plazo sobre el apego, a la vez que propone la necesidad de cualificar la reconocida asociación directa entre vínculos sociales y este concepto. Un mayor conocimiento sobre apego al lugar en contextos de desastres puede favorecer la reconstrucción y la mitigación frente a nuevas amenazas.
\end{abstract}

Palabras clave: apego al lugar, desastres, confianza interpersonal, experiencia del desastre, Chaitén

This study investigates the place attachment of the inhabitants of Chaitén, Chile, a community affected by a volcano eruption that destroyed a large part of the city in 2008. The article explores the associations of place attachment with the direct experience of disaster and interpersonal trust. To answer this question, a survey was designed which comprised instruments that measure place attachment, residence, and interpersonal trust. For the latter, the instrument measured trust in old and new inhabitants. The survey was administered in 2015 to 188 inhabitants of Chaitén, who were selected from a two-stage sample stratified by sector (north and south of Chaitén). Based on linear regressions, results indicate that direct experience of the disaster increases place attachment and slightly moderates the association between it and interpersonal trust in the community. Trusting old inhabitants increases place attachment only for people who did not experience the eruption. No association was found between trust in new inhabitants and place attachment. This study contributes to scientific knowledge of place attachment by suggesting that disasters have positive long-term consequences for attachment, while also proposing the need to qualify the well-known direct association between social bonds and this concept. Greater knowledge about place attachment in disaster contexts can foster reconstruction and mitigation processes when dealing with new threats.

Keywords: place attachment, disasters, interpersonal trust, disaster experience, Chaitén

Las personas tienen vínculos de carácter subjetivo con los lugares en los que habitan. Para dar cuenta del conjunto de estos vínculos, estudios en psicología ambiental han propuesto el concepto de apego al

Luis Maldonado, Instituto de Sociología, Pontificia Universidad Católica de Chile, Santiago, Chile; Edmundo Kronmüller, Escuela de Psicología, Pontificia Universidad Católica de Chile, Santiago, Chile; Ignacio Gutiérrez Crocco, Centro de Investigación para la Gestión Integrada del Riesgo de Desastres, Santiago, Chile.

Este estudio recibió apoyo económico de la Comisión Nacional de Investigación Científica y Tecnológica de Chile, a través del Proyecto FONDAP 15110017.

La correspondencia relativa a este artículo debe ser dirigida a Luis Maldonado, Instituto de Sociología, Pontificia Universidad Católica de Chile, Avda. Vicuña Mackenna 4860, Macul, Santiago, Chile. E-mail: lmaldona@uc.cl 
lugar. El concepto ha sido fuente de un importante desarrollo metodológico, lo que ha resultado en una amplia variedad de propuestas conceptuales y estrategias de medición. Frente a esta diversidad conceptual y metodológica, varios autores han planteado la necesidad de desarrollar consensos mínimos que permitan hacer avanzar al conocimiento científico sobre apego al lugar (Hernández, Hidalgo \& Ruiz, 2014; Lewicka, 2011; Scannell \& Gifford, 2010).

En los últimos años, investigadores han tratado de avanzar en esta línea, sugiriendo algunos puntos en común entre una cantidad significativa de estudios. Primero, un número considerable de autores está de acuerdo en que el tema en cuestión son los vínculos entre humanos y lugares (Manzo \& Devine-Wright, 2014). Segundo, tal como Lewicka (2011) ilustra, habría consenso entre varios investigadores en que dichos vínculos tienen variadas expresiones que se manifiestan en distintas dimensiones (e.g., físico, afectivo, cognitivo y/o conductual). Tercero, siguiendo a Hernández et al. (2014), autores también han planteado la necesidad de avanzar en los mecanismos explicativos del apego al lugar.

Con el fin de contribuir al conocimiento sobre algunos de estos puntos de acuerdo, nuestra investigación tuvo por objetivo estudiar el apego al lugar de los habitantes de una comunidad que ha experimentado alteraciones profundas del medio ambiente en el que habitan, producto de un desastre. Para ello, investigamos el caso de la ciudad de Chaitén, en la Patagonia chilena, en el contexto de la erupción volcánica que la afectó el año 2008.

La erupción del volcán Chaitén, ubicado a 10 kilómetros al noreste de la ciudad, afectó a más de 8000 personas que vivían en ella o en sus inmediaciones. Producto de la destrucción de la infraestructura física y los riesgos inminentes para la población, el gobierno de Chile ordenó la evacuación total de la población de la ciudad Chaitén y de otras localidades en un radio de 50 kilómetros en torno al volcán (Berezin, 2015; Espinoza, Espinoza \& Fuentes, 2015). Como resultado, 8119 personas fueron evacuadas, principalmente hacia localidades del sur de Chile, tales como Puerto Montt, Castro y Osorno (Chile, Ministerio del Interior y Seguridad Pública, 2014). Debido a los altos riesgos para el bienestar de la comunidad, el Estado de Chile declaró a la ciudad de Chaitén como inhabitable, por lo que su reocupación fue prohibida por este desde mayo del 2008 hasta el año 2011. En la actualidad, Chaitén es habitada por cerca de 2000 personas.

El carácter radical del proceso de reocupación de Chaitén posterior al desastre lo configura como un caso de análisis particularmente interesante para entender la relación entre apego al lugar y la experiencia de vivir un desastre y sus consecuencias personales y sociales. Nuestra investigación indagó sobre el apego al lugar de los habitantes actuales de Chaitén y su relación con dos fenómenos, uno de la esfera individual y el otro del ámbito microsocial. Con respecto al primero, nuestro estudio se preguntó por la relación entre la vivencia directa del desastre y el nivel de apego al lugar en la etapa post-desastre. Sobre el segundo, estudiamos vínculos sociales en términos de confianza social hacia antiguos y nuevos habitantes de Chaitén y nos preguntamos por el efecto de la vivencia del desastre sobre la asociación entre vínculos sociales y apego al lugar.

Así, nuestra investigación contribuiría de varias maneras. Primero, investigaciones han llamado la atención sobre la importancia de disrupciones del ambiente como desastres naturales para estudiar apego al lugar, pues en ellas se dejan ver con mayor claridad los mecanismos explicativos que generan los vínculos entre humanos y lugares (Devine-Wright, 2011; Mihayloy \& Perkins, 2014). Sin embargo, estudios sobre apego al lugar en contextos de desastres naturales son escasos (Berroeta, Ramoneda \& Opazo, 2015; Berroeta, Ramoneda, Rodriguez, Di Masso \& Vidal, 2015; Ruiz \& Hernández, 2014). En este sentido, nuestra investigación contribuiría al estudio de apego al lugar al aportar evidencia sobre cómo los vínculos entre humanos y lugar responden a la experiencia directa de un fuerte cambio del ambiente, luego de pasados varios años de una catástrofe. Esto es particularmente relevante en el contexto de la sociedad chilena, dada su larga historia con desastres socionaturales. Segundo, la evidencia sobre vínculos sociales (e.g., capital social) y apego al lugar en general descansa en una concepción de los lazos sociales que pone el foco en contextos comunitarios formados por familiares, amigos y vecinos (Lewicka, 2011). Sobre la base de dicho supuesto teórico, varios estudios de apego consistentemente muestran una asociación directa entre ambos constructos (para una revisión de estos estudios, ver Mihayloy \& Perkins, 2014). Nuestro estudio llama a tensionar este resultado. Investigaciones recientes sobre capital social indican que concepciones comunitarias de los vínculos sociales pueden obscurecer patrones específicos de relaciones intergrupales (Abascal \& Baldassarri, 2015). Siguiendo a estas investigaciones, nosotros intentamos capturar el rol de distintos tipos de relaciones intergrupales, por medio de la distinción entre confianza en antiguos y en 
nuevos habitantes de Chaitén, e indagamos si las asociaciones entre apego al lugar y ambos tipos de confianza interpersonal varían entre las personas que experimentaron el desastre y las que no lo vivieron.

\section{Chaitén y la Erupción Volcánica del 2008}

Información censal para el periodo previo al desastre señala que Chaitén tenía una población de 4065 habitantes a nivel urbano en el 2002 (Chile, Ministerio del Interior y Seguridad Pública, 2014). La erupción del volcán Chaitén comenzó el 2 de mayo del 2008 y continuó hasta finales del 2009. Expertos consideran a esta erupción como una de las mayores de los últimos 30 años a nivel global (Major \& Lara, 2013). Si bien no se registraron fatalidades humanas como consecuencia directa de la erupción, la gran cantidad de material piroclástico acumulado, removido por intensas precipitaciones que afectaron la zona 10 días después de la primera explosión, causó aluviones volcánicos y desborde del río Blanco, lo que generó graves daños en la ciudad (Pierson, Major, Amigo \& Moreno, 2013).

Dada la evacuación, el gobierno central determinó la construcción de una nueva localidad a 10 kilómetros al norte de la ciudad devastada, llamada Santa Bárbara. Junto a este mega proyecto de refundación de una comunidad entera, el Estado entregó una serie de beneficios a los afectados por la catástrofe. Ofreció a las personas que tenían propiedades en la ciudad de Chaitén la compra de sus viviendas y se distribuyeron bonos en dinero efectivo y subsidios habitacionales para la reubicación permanente de la población en otros lugares del sur de Chile como Puerto Montt, Castro y Santa Bárbara.

Obviando la prohibición de ocupación de la ciudad devastada, ya durante el 2008 algunos pobladores toman la decisión de regresar a Chaitén y ocupar sus viviendas ilegalmente. La decisión de retornar se propagó rápidamente entre otros habitantes de Chaitén, formándose un grupo contestatario a la decisión del Estado de no reconstruir Chaitén. Dicho grupo estuvo compuesto principalmente por vecinos y vecinas con posiciones sociales ventajosas, presionando fuertemente a las autoridades para reconstruir la ciudad (Mandujano \& Rodríguez, 2016). Dicha presión brindó sus frutos y las autoridades terminaron descartando el proyecto de reconstrucción de la ciudad en Santa Bárbara, resolviendo reconstruir Chaitén en el mismo lugar, pero habilitando la ocupación solo del sector norte (Chile, Ministerio del Interior y Seguridad Pública, 2014; Ugarte Caviedes \& Salgado Vargas, 2014). No es hasta mayo del 2017 que el sector sur es declarado habitable por el Concejo Comunal de Chaitén. Cabe destacar que estudios recientes confirman el riesgo al que se expone la población en toda la ciudad (Lara \& Calderón, 2015). Información reciente indica que tanto el sector norte como el sur de la ciudad se encuentran habitados, con una población estimada de 1643 habitantes (Chile, Instituto Nacional de Estadísticas, 2018).

\section{Apego al Lugar y Desastres}

\section{Definiciones de Apego al Lugar}

En términos generales, el apego al lugar se refiere al vínculo subjetivo que desarrollan las personas con los lugares. Sin embargo, las diversas perspectivas desde las que se ha abordado este vínculo a lo largo de las últimas décadas han generando una amplia discusión respecto de sus definiciones, aplicaciones y métodos (Lewicka, 2011; Manzo \& Devine-Wright, 2014; Scannell \& Gifford, 2010). La complejidad del constructo radica en las múltiples facetas que implica. Su estudio ha abordado dimensiones relacionadas con el actor del apego, las características del lugar como objeto de apego y los procesos psicológicos en acción, entre los que se distinguen, a su vez, elementos afectivos, cognitivos y conductuales (Scannell \& Gifford, 2010). En este marco multidimensional, distintas propuestas ponen énfasis en el vínculo con la naturaleza, en la relación de dependencia con el lugar o en el vínculo social con la comunidad que habita un mismo lugar (Hidalgo \& Hernández, 2001; Lewicka, 2011; Raymond, Brown \& Weber, 2010). Así, autores han intentado distinguir el concepto de apego al lugar de otros, como identidad de lugar (Devine-Wright, 2011; Proshansky, Fabian \& Kaminoff, 1983). Sin embargo, cabe destacar que su asociación con estos conceptos ha permanecido difusa, sin consenso respecto a si corresponde a un factor dentro de constructos mayores o si es uno al cual otras dimensiones están subordinadas (Hernández et al., 2014).

Especial atención se ha puesto a la relación entre el apego al lugar y los vínculos con la comunidad. Mientras algunas aproximaciones reconocen la comunidad como un atributo del lugar que debe ser incorporado en la evaluación del apego al lugar (Raymond et al., 2010), otros los distinguen como constructos provenientes de perspectivas diferentes. Autores en esta segunda línea sugieren que el estudio 
del apego al lugar debe focalizarse en el vínculo con el lugar como una entidad indivisible en sus atributos, en cuanto las personas experimentan y se apegan a los lugares como entidades holísticas (Russell \& Ward, 1982; Williams, 2014). En este sentido, el vínculo específico con las personas es mejor descrito por conceptos provenientes de la sociología comunitaria, como el apego a la comunidad y el capital social, respecto de los cuales se puede evaluar el apego al lugar en una relación de influencia (Anton \& Lawrence, 2016; Trentelman, 2009).

Para nuestra investigación hemos considerado uno de los modelos más utilizados en la literatura sobre apego al lugar, el cual lo comprende como un constructo de primer orden compuesto por dos dimensiones (Williams \& Vaske, 2003). La primera es la dependencia del lugar y refleja la importancia que tiene un lugar en tanto sus características físicas permiten lograr objetivos específicos o realizar actividades valoradas por las personas (Jorgensen \& Stedman, 2001; Stokols \& Shumaker, 1981; Williams \& Roggenbuck, 1989, Octubre). La segunda es la identidad de lugar y se refiere a la importancia de un lugar en tanto repositorio de emociones y lazos simbólicos que definen quienes somos (Proshansky et al., 1983; Williams \& Roggenbuck, 1989, Octubre). Este modelo se enfoca en lo que algunos autores denominan la dimensión biofísica del apego al lugar, poniendo el foco en el lugar como escenario, no distinguiendo entre sus atributos sociales y físicos como objetos independientes de apego (Trentelman, 2009; Williams, 2014).

Las divergencias teóricas han complejizado, a la vez, los métodos para estudiar el apego al lugar. Existe un inconcluso debate respecto de la preferencia de aproximaciones cuantitativas versus métodos cualitativos. Estas preferencias se comprenden en parte por las definiciones con las que se entiende el lugar, ya sea como objeto de apego o como origen de sentido (Williams, 2014). En esta discusión, son aquellos enfocados en la primera definición los que han perseguido la evaluación de la intensidad del vínculo, más que el proceso mediante el cual se construye el sentido de un lugar. Las investigaciones en esta línea han propuesto varias escalas para medir apego al lugar. Un número significativo de investigaciones ha usado el instrumento desarrollado por Williams y Vaske (2003), el cual está diseñado para evaluar la intensidad en términos del modelo bidimensional, identificando la identidad de lugar y la dependencia al lugar como constituyentes del apego al lugar. Otras escalas utilizadas en la literatura son la escala global de apego al lugar de Hidalgo y Hernández (2001) y el instrumento desarrollado por Scannell y Gifford (2010) para capturar componentes sociales y espaciales de apego. No obstante, la utilidad de agregar aspectos específicos del lugar ha sido cuestionada por no ser coherente con una experiencia holistica del mismo (Williams, 2014).

\section{Predictores del Apego al Lugar}

La multidimensionalidad del concepto de apego al lugar se refleja también en los factores que lo influyen. En la literatura podemos identificar tres grandes categorías de determinantes. Una primera categoría, que fue de particular interés para nuestra investigación, dice relación con los vínculos sociales entre miembros de una comunidad. Estos han sido tratados en la literatura de diversos modos. Tal como ya mencionamos, mientras algunos estudios consideran a los vínculos sociales y al apego al lugar como constructos teóricos distintos, otras investigaciones consideran los vínculos sociales como una dimensión del concepto de apego al lugar. Siguiendo esta última opción teórica, Raymond et al. (2010) sostienen que los significados asociados a un lugar están mediados por las interacciones sociales. Estos autores consideran al contexto de la comunidad, conformado por el sentimiento de pertenencia a círculos sociales o por la membrecía a grupos de personas, como componente esencial de lo que ellos llaman la dimensión social del apego al lugar.

En el grupo de estudios que consideran a los vínculos sociales y al apego al lugar como constructos teóricos distintos, podemos encontrar investigaciones sobre los vínculos sociales como predictores del apego al lugar. Al respecto, Lewicka (2011) señala que el tipo de lazo social estudiado por lo general es el capital social local o comunitario, es decir, vínculos sociales conformados entre amigos, vecinos o familiares. Además, esta autora señala que en general la evidencia muestra que la fuerza de los lazos comunitarios predice directamente el apego al lugar y que este resultado es consistente entre los estudios. Como mecanismo explicativo, algunos autores sugieren que los lazos sociales en los lugares de residencia refuerzan la significación de estos últimos y, por lo tanto, contribuyen a fortalecer los vínculos emocionales (Mihayloy \& Perkins, 2014).

La literatura reciente en ciencias sociales ha puesto en cuestión algunos supuestos que están a la base de las concepciones del capital social que ponen el foco en vínculos comunitarios. Tal como señalan Abascal 
y Baldassarri (2015), este tipo de conceptualizaciones dependen de alguna noción de solidaridad mecánica que está basada en la similitud social y homogeneidad cultural, lo que obscurece patrones alternativos de relaciones intergrupales. Para dar cuenta de la diversidad de los lazos sociales, estudios de capital social distinguen los vínculos con familiares y amigos de los lazos sociales con extraños. Así, tenemos, por ejemplo, la distinción entre confianza interpersonal particularizada y generalizada (Delhey, Newton \& Welzel, 2011; Freitag \& Bauer, 2013). Si suponemos que una relación de confianza social está compuesta por un ego que confía y un alter que es el depositario de esa confianza, la confianza particularizada (in-group trust) se refiere a la confianza hacia personas que el ego conoce personalmente a partir de sus interacciones diarias con ellas (e.g., amigos, vecinos y familiares). La confianza generalizada (out-group trust) se refiere, más bien, a vínculos del ego con personas que están más allá de sus círculos cercanos e incluye extraños (e.g., personas con las que se puede encontrar aleatoriamente en la calle). Según nuestro conocimiento, este tipo de distinciones ha sido investigada escasamente en la literatura de apego al lugar. Uno de los pocos antecedentes es el trabajo de Lewicka (2005), quien discute la posibilidad de que un aumento de la fuerza de los lazos con extraños puede estar asociado con una disminución del apego al lugar. Sin embargo, esta autora no reporta evidencia directa sobre esta asociación, pues su foco está en el rol del capital cultural.

Un segundo grupo de determinantes del apego al lugar está conformado por variables sociodemográficas. En su revisión reciente de la literatura, Lewicka (2011) encuentra los siguientes patrones: (a) a menor ingreso y educación existe mayor apego al lugar, (b) a mayor tiempo de residencia y mayor edad existe mayor apego al lugar y (c) las mujeres y ser propietario de una residencia en un lugar están directamente asociados con apego a ese lugar. Finalmente, la tercera categoría de predictores se refiere a aspectos físico-ambientales, siendo las más difícil de conceptualizar y medir, dada la multiplicidad de particularidades físicas que pueden configurar un lugar (Lewicka, 2011).

\section{Apego al Lugar y Desastres}

Los desastres tensionan de tal manera el vínculo entre una persona y su lugar que pueden ser considerados como una vía privilegiada de acceso a las dinámicas del apego al lugar y a su relación con elementos objetivos y subjetivos propios del vivir expuesto a amenazas naturales. En efecto, en su tipología de los tipos de apego, Low (1992) ya proponía un tipo definido por la pérdida o destrucción de un lugar, ya sea por motivos de guerra, exilio, migración o desastre. A pesar de lo anterior, en la actualidad son pocos los estudios realizados que aborden directamente la relación entre los desastres y el apego al lugar. Sin embargo, se observa una tendencia positiva en el interés por esta relación, motivada principalmente por los efectos del cambio climático (De Dominicis, Fornara, Cancellieri, Twigger-Ross \& Bonaiuto, 2015).

Un área de estudio que relaciona apego al lugar con desastres la constituyen investigaciones sobre percepción de riesgo. Esta denota la interpretación que tienen las personas del riesgo al que está asociado un determinado evento y que puede estar determinada por factores biológicos, psicológicos o sociales (Slovic, 2000). En el campo de la psicología ambiental, el apego al lugar se ha estudiado como un determinante de la percepción de riesgo. Los estudios muestran evidencia contradictoria. Algunos estudios han hallado que un mayor apego al lugar se asociaría con una menor percepción del lugar como peligroso (Collins, 2009; Dallago et al., 2009), mientras otros han encontrado el patrón inverso (Fátima, 2013). Igual controversia existe sobre la relación entre el nivel objetivo de riesgo de una localidad, la percepción de riesgo y el apego al lugar: en algunos casos un mayor apego al lugar aumentaría la percepción de riesgo en lugares de bajo riesgo, pero en otros la atenuaría (Fátima, 2013). Finalmente, se ha mostrado que el apego puede moderar la relación entre percepción de riesgo y preparación: el apego al lugar afecta inversamente la relación entre percepción de riesgo y la toma de medidas, tales como la búsqueda de información y el almacenamiento de productos potencialmente necesarios en caso de inundaciones (De Dominicis et al., 2015; Mishra, Mazumdar \& Suar, 2010).

Otra área de estudio que vincula el apego al lugar y los desastres está relacionada con los procesos de desplazamiento por un desastre y el posterior retorno al lugar de origen. Chamlee-Wright y Storr (2009) observaron que el apego al lugar motivaba a las personas a regresar a New Orleans después del desastre del huracán Katrina. En relación con las poblaciones desplazadas, Berroeta et al. (2015) indagaron en los vínculos socioespaciales de la propia población de Chaitén luego de la erupción del volcán, reubicada en Puerto Montt, Chiloé y Futaleufú, encontrando un nivel de apego y de identidad con el lugar de origen mayor al nivel de estos constructos en la residencia de destino. Según estos autores, las diferencias entre el lugar pasado y presente dan cuenta de un quiebre significativo del vínculo con el lugar presente. Dado que 
las experiencias directas con el espacio y las personas que lo habitan son centrales para la configuración del significado de lugar, dicho quiebre sugiere que las personas no han logrado establecer vínculos físicos y sociales con el lugar de residencia actual (Berroeta et al., 2015).

Más directamente relacionado con apego al lugar y experiencia de desastre, Ruiz y Hernández (2014) examinan la influencia de episodios de actividad volcánica submarina en el apego al lugar e identidad de lugar entre habitantes de las islas Canarias (España) en base a entrevistas aplicadas entre septiembre y diciembre del 2011. Sus resultados indican que cambios suscitados en el ambiente por este tipo de desastres están asociados con una disminución del apego, pero no habría asociación con la identidad de lugar. Es importante notar, sin embargo, que el caso estudiado por Ruiz y Hernández (2014) correspondió a erupciones submarinas, donde el daño en términos de infraestructura y vidas humanas fue menor. Por esto, queda abierta la pregunta por el efecto en el apego que tienen los desastres que ocasionan fuertes cambios físicos y sociales en el lugar habitado, como fue el caso de la erupción del volcán Chaitén.

\section{Preguntas de Investigación e Hipótesis}

La revisión de la literatura y la narración del caso de Chaitén nos lleva nuevamente a nuestras preguntas de investigación: ¿Cómo está asociada la experiencia directa de un desastre con el apego al lugar en la etapa post-desastre? ¿Cómo es la asociación entre confianza interpersonal y el nivel de apego al lugar en dicha etapa? ¿De qué manera esta asociación varía según la experiencia directa de un desastre? Las respuestas a las que llegamos en esta investigación están guiadas por el siguiente set de hipótesis.

\section{Apego al Lugar y Experiencia Directa del Desastre}

Como señalan Ruiz y Hernández (2014), un desastre puede producir cambios en el apego al lugar en tanto modifica el control que las personas tienen sobre el lugar habitado. Dicho mecanismo explicativo puede producir efectos del desastre, los que persisten varios años después de sucedida la catástrofe, especialmente si el daño producido ha sido mayor. Por ejemplo, una catástrofe natural puede tener efectos positivos en el apego al lugar en el largo plazo, en tanto puede reforzar el control de las personas sobre el lugar. Dicho efecto debiera ser particularmente significativo para las personas que retornan al lugar devastado.

Chaitén y su desastre ilustran el modo en que esta asociación positiva puede ocurrir. Primero que todo, los retornados presentan experiencias y actividades que pudieron aumentar su nivel de control del lugar. En efecto, gran parte de los retornados no solo reconstruyeron sus lugares físicos, sino también formaron parte del grupo contestatario que se movilizó para la reconstrucción de la ciudad, generándose actividades diarias de reforzamiento del apego hacia Chaitén (Ugarte Caviedes \& Salgado Vargas, 2014). Segundo, esta movilización social también tiene efectos simbólicos. Tal como señalan Mandujano y Rodríguez (2016), durante el proceso de recuperación, se genera prontamente una distinción social entre los "vendidos al Estado" (habitantes que aceptaron las condiciones de las autoridades para vivir en la zona) y los "auténticos chaiteninos", perteneciendo a este último grupo principalmente los retornados. Dicha distinción evidencia una fuerte asociación de la identidad del grupo de retornados con el lugar reocupado. En suma, las actividades y experiencias de los retornados, así como los efectos simbólicos de estas, pueden generar un mayor control del lugar reocupado, lo cual, a su vez, se traduce en un mayor apego al lugar habitado (Chaitén). Esto nos lleva a nuestra primera hipótesis:

H1: La experiencia directa de un desastre aumenta el apego al lugar en la etapa post-desastre.

\section{Apego al Lugar y Confianza Interpersonal}

El segundo grupo de hipótesis se refiere a los vínculos sociales. La literatura indica que los vínculos sociales, muchas veces operacionalizados bajo el concepto de capital social, tienen una relación directa con apego al lugar. Dicho resultado es consistente en un número significativo de estudios (Lewicka, 2010, 2011). Sin embargo, una catástrofe natural también puede tensionar esta relación. En efecto, la evidencia existente sobre la vida social en Chaitén post-desastre sugiere un claro quiebre de los vínculos comunitarios (Arteaga \& Ugarte, 2015; Berroeta et al., 2015). Como ilustración de este panorama social, un dirigente social entrevistado por Mandujano y Rodríguez (2016) en el 2014 señala lo siguiente: 
No existe algo colectivo en Chaitén, es muy difícil armarlo. Al llegar personas de otros lugares, se perdió lo que teníamos de original acá. Un treinta por ciento de la gente no era de acá antes. Uno se encuentra a cada rato con personas que vienen de afuera, y es difícil hacer comunidad con gente que uno no conoce, esas personas. Nosotros sabíamos quiénes eran los vecinos, sabíamos los apellidos, sus problemas. (p. 71)

La ciudad de Chaitén en la actualidad es, entonces, un nuevo lugar en donde conviven los habitantes pre-catástrofe y nuevos habitantes, siendo difícil la generación de vínculos entre ambos grupos. Con el fin de capturar las implicancias que puede tener esta nueva distinción social para la asociación entre vínculos sociales y apego al lugar, nuestra investigación levantó información sobre niveles de confianza interpersonal de los entrevistados hacia las personas que viven actualmente en Chaitén (en el año 2015), pero que no vivieron en este lugar antes de la erupción (nuevos habitantes) y hacia los que vivían en él antes del desastre (antiguos habitantes). Con esta distinción buscamos explorar distintos patrones de relaciones intergrupales. Para los habitantes que vivían en Chaitén antes de la catástrofe y que la experimentaron, el grupo de antiguos habitantes puede representar un círculo de cercanos depositario de un tipo de confianza particularizada. basada en una historia de interacciones en el lugar habitado antes del desastre. Por su parte, los nuevos habitantes pueden ser sujetos de confianza generalizada, en tanto representan un tipo de alter que no pertenece a círculos de amigos o familiares. En este sentido, estos dos tipos de confianza nos permiten explorar en detalle la asociación entre vínculos sociales y apego al lugar, en tanto pueden sugerir distintos tipos de asociaciones entre confianza y vínculos persona-lugar.

Conceptualmente, confianza interpersonal se refiere a las expectativas que tiene un ego sobre la confiabilidad de un alter y es un aspecto clave del capital social (Putnam, 1995; Yamagishi, Cook \& Watabe, 1998). Este tipo de expectativas dependen fuertemente del sentido de seguridad y control que sienten las personas. En general, ambos factores tienden a darse en grupos con fuertes lazos familiares y de amistad (Ermisch \& Gambetta, 2010). Sin embargo, si bien los lazos familiares promueven un sentido de seguridad al interior de este tipo de círculos sociales, estos pueden dañar la confianza generalizada en extraños (Abascal \& Baldassarri, 2015). Según nuestro conocimiento, no hay antecedentes teóricos en la literatura de apego de lugar que nos entreguen herramientas para entender cómo la vivencia de desastres puede afectar el mecanismo explicativo de confianza social que recién hemos expuesto. Podríamos esperar que, en el contexto de desastres, el rol del sentido de seguridad y del control en la generación de confianza muestre patrones heterogéneos que estarían dados por la vivencia de una catástrofe. En efecto, podríamos especular que los habitantes que vivieron la catástrofe exhiben una asociación directa entre confianza hacia los antiguos habitantes y apego al lugar, pues ellos representan a círculos de cercanos (familiares, amigos, vecinos) que entregan sentido de seguridad y control, lo que, a su vez, aumenta el apego al lugar. Además, podemos esperar una falta de asociación entre apego y la confianza hacia los nuevos habitantes, dada la falta de capacidad de control y la sensación de inseguridad en estos últimos, lo que puede generarse por la falta de vida comunitaria en Chaitén actual. Por su parte, las personas que no vivieron la catástrofe tal vez se comportan en línea con la evidencia existente en la literatura y, por lo tanto, esperaríamos una asociación directa entre confianza y apego al lugar, independientemente del grupo social que es objeto de la confianza. Los nuevos habitantes tienen que invertir en la generación de lazos con la comunidad y no tienen aún la necesidad de control, dado la ausencia de lazos familiares en Chaitén. En otras palabras, planteamos que la vivencia de la catástrofe modera la asociación entre confianza social y apego al lugar del siguiente modo:

H2a: Confiar en las personas que vivían en Chaitén antes de la erupción de 2008 aumenta el apego al lugar en la etapa post-desastre para las personas que vivieron y no vivieron la catástrofe.

H2b: Confiar en los nuevos habitantes aumenta el apego al lugar en la etapa post-desastre solo para las personas que no vivieron la catástrofe. Para los que vivieron el desastre, este tipo de confianza interpersonal no está asociada con apego al lugar.

\section{Método}

\section{Participantes}

La población objeto del estudio son personas de 18 años o más que residían en la ciudad de Chaitén en el momento de aplicación de la encuesta (noviembre y diciembre de 2015). Diseñamos una muestra estratificada por sector (norte y sur de Chaitén) y bietápica con dos niveles de selección. Definimos ambas 
unidades de muestreo del siguiente modo: (a) unidad de muestreo primaria fue vivienda y (b) unidad de muestreo secundaria fue persona de 18 o más.

El tamaño muestral objetivo fue de 251 entrevistas, para obtener un error muestral de diseño de $\pm 5,8$ puntos porcentuales. Estimamos este error muestral suponiendo una variable dicotómica con varianza máxima (por ejemplo, $50 \%$ 1s y $50 \%$ os) con un nivel de confianza del $95 \%$, muestreo aleatorio simple y una población de 1732 personas en Chaitén, 1180 en el sector norte y 552 personas con ocupaciones irregulares en el sector sur. El diseño lo realizamos en base a los datos de Ministerio del Interior y Seguridad Pública de Chile (2014), previo al censo de 2017 y la habilitación del sector sur.

Cabe destacar que, debido a la falta de datos actualizados sobre las viviendas ocupadas, nuestro proyecto contempló la realización de un empadronamiento general de la ciudad durante octubre de 2015 para identificarlas, el cual arrojó un total de 491 viviendas ocupadas con uso habitacional, 271 en el sector norte y 220 en el sector sur. Entrevistamos a 188 habitantes de Chaitén, de los cuales 106 son mujeres y el promedio de edad es de 45,5 años. Respecto del tamaño muestral objetivo, hay casos no logrados. Esto implica un aumento del error muestral de $\pm 5,8$ a $\pm 6,8$ puntos porcentuales. Sobre la base de la muestra final de 188, calculamos para la variable dependiente del estudio —el puntaje estandarizado de nuestra variable dependiente- el efecto del diseño complejo de la encuesta. Este es 1,12 y su intervalo de confianza al $95 \%$ es $[-0,21,0,09]$. La tasa de respuesta general fue de $66 \%$. Dada la presencia de datos perdidos, para nuestros análisis utilizamos una muestra de 170 casos.

\section{Instrumentos}

Batería de apego al lugar. Nuestra variable dependiente apego al lugar fue medida con la traducción al español de la batería de preguntas diseñadas por Williams y Vaske (2003). Escogimos esta batería por las siguientes razones. Tal como ya señalamos, esta es una de las más usadas en la literatura (Lewicka, 2011), siendo su validez y confiabilidad confirmadas en diferentes contextos (Raymond et al., 2010). Sobre la base de este patrón, nosotros usamos el constructo de dos dimensiones y trasladamos nuestro foco de atención desde una comprensión detallada de la variable dependiente hacia factores específicos que pueden influenciar el apego al lugar. Segundo, existen antecedentes de uso de este instrumento en el estudio de desastres (Anton \& Lawrence, 2016). Asimismo, el diseño original de Williams y Roggenbuck (1989, Octubre) evalúa el apego, independiente de la experiencia de residencia, pudiendo aplicarse a habitantes transitorios, lo que es común en lugares como Chaitén. Estos antecedentes nos dieron confianza para usar el instrumento en contexto de desastre.

La batería consta de 12 ítems que preguntan, en una escala Likert de 5 puntos, el nivel de acuerdo con afirmaciones como "Ningún lugar puede compararse con Chaitén" o "Usted siente que Chaitén es parte de usted" (la escala se puede ver en el Anexo 1). En general, el instrumento es utilizado para generar dos constructos que miden las dimensiones Identidad y Dependencia. Sin embargo, nuestra evaluación psicométrica del instrumento indica que existe solo una dimensión en los datos recolectados de la población de Chaitén. En base a este resultado, decidimos trabajar solo con una medición de apego, la cual generamos a través de la suma de 11 ítems del instrumento. Siguiendo la recomendación de Williams y Vaske (2003), no utilizamos el ítem 12, el cual apunta a la dimensión Dependencia. El constructo generado presentó una consistencia interna de 0,969 (alfa de Cronbach). Como estrategia de validación del constructo de nuestra variable dependiente, cabe destacar que también estimamos modelos de regresión con las dimensiones Identidad y Dependencia como variables dependientes separadas y el set de predictores que describimos más adelante, sin encontrar diferencias substantivas con los modelos que presentamos en nuestro artículo. El análisis psicométrico completo se encuentra en el Anexo 2.

Cuestionario sobre residencia y confianza. La experiencia directa del desastre, que nos permitió categorizar a las personas como habitantes retornados o nuevos, la medimos a través de una pregunta que consultó si los entrevistados vivían (o no) en Chaitén cuando sucedió la erupción del volcán, configurando una variable categórica, en donde 1 indica a las personas que vivian y 0 a las que no vivían.

Guiados por las hipótesis 2a y 2b, medimos confianza social en dos grupos: antiguos y nuevos habitantes. Sobre la base de los antecedentes teóricos que hemos mencionado, nuestro objetivo con estas mediciones era capturar patrones de confianza particularizada y generalizada, respectivamente. Siguiendo la literatura sobre medición de confianza social (Delhey et al., 2011; Freitag \& Bauer, 2013), nuestros 
indicadores utilizan tres preguntas que consultan por el nivel de confianza y que usan una escala de respuesta con cuatro categorías: 1 (confía completamente), 2 (confía algo), 3 (confía poco) y 4 (confía nada).

Para medir confianza en personas que vivian en Chaitén antes de la erupción de 2008, utilizamos dos preguntas que capturan el nivel de confianza en gente que vivía en la ciudad antes del desastre. La primera mide el nivel de confianza en antiguos habitantes que volvieron a vivir a Chaitén después del desastre y la segunda, la confianza en antiguos habitantes que no volvieron. En base a estas preguntas, construimos una variable categórica con los siguientes valores: 1 captura las respuestas de los entrevistados que afirmaron confiar completamente o algo en antiguos habitantes que volvieron y en antiguos habitantes que no volvieron; 0 denota las respuestas de los que respondieron confiar poco o nada en antiguos habitantes que volvieron y que no volvieron a Chaitén. En relación con la confianza hacia nuevos habitantes, nuestra encuesta consultó por el nivel de confianza hacia gente que no vivía en Chaitén antes de la erupción de 2008 y que vive actualmente en este lugar. Del mismo modo que para los antiguos habitantes, transformamos la escala original de 4 categorías en una variable binaria que agrupa 1 (confía completamente) y 2 (confía algo) en una categoría y 3 (confía poco) y 4 (confía nada) en otra.

Cuestionario sobre variables de control. Además, recogimos datos para las siguientes variables de control: tiempo (en años) de residencia en Chaitén, sexo, situación laboral, nivel educacional e ingreso mensual del hogar. Respecto de este último constructo, utilizamos dos variables dicotómicas que capturan los cuartiles de la distribución del ingreso: el cuartil más alto $(Q 4)$ y los cuartiles entre el $25 \%$ y el $75 \%$ de la distribución de la variable ingreso (Q2-Q3), siendo el cuartil más bajo (Q1) la categoría de referencia. También agregamos una variable binaria en donde 1 denota a las personas con información perdida de ingreso.

Además de las variables mencionadas, controlamos por el nivel percibido de exposición individual al riesgo de desastre, pues la literatura sobre desastres sugiere que esta variable podría estar asociada con la experiencia del desastre (Tierney, 2014). Además, este factor podría influenciar el apego al lugar, en tanto la percepción de riesgo esté asociada con el sentido de seguridad y de control sobre el lugar. Siguiendo Bronfman, Cisternas, López-Vázquez \& Cifuentes (2016), utilizamos la pregunta ¿A cuánto riesgo cree que está expuesto/a usted producto de una nueva erupción del volcán Chaitén?. La escala de respuesta tiene 7 niveles y se mueve entre 1 (ningún riesgo) y 7 (mucho riesgo). Utilizamos el indicador como variable continua.

Finalmente, para medir el tipo de vínculo con la vivienda habitada por el entrevistado (propiedad), generamos, en base a la información de la encuesta, una variable con tres condiciones que denotan la situación de propietario, arrendatario y otra para los que no están en las dos primeras condiciones. Incluimos estas condiciones en los análisis a través de dos variables categóricas dummies, dejando la condición de propietario como categoría de referencia.

\section{Procedimiento}

El estudio contó con la aprobación del Comité de Ética y Seguridad de la Investigación de la Pontificia Universidad Católica de Chile.

La encuesta se aplicó durante noviembre y diciembre de 2015. Contratamos a ocho encuestadores con experiencia en aplicación de entrevistas. Los encuestadores fueron capacitados por el jefe de campo de nuestro estudio para aplicación de la encuesta. Los participantes fueron contactados por un encuestador directamente en sus viviendas. Cada encuestador acudió a las viviendas seleccionadas aleatoriamente y seleccionó mediante la tabla Kish a uno de los habitantes de 18 años o más, al cual se contactó e invitó a participar. A aquellos que accedieron a participar se les presentó un consentimiento informado que explicaba el objetivo de la investigación, la naturaleza voluntaria de la participación, el resguardo de la confidencialidad de las respuestas y el uso de la información solo para objetivos académicos. Luego de firmado el consentimiento, se aplicó una encuesta cara cara, asignando un código de folio a cada participante para mantener el anonimato. Los cuestionarios respondidos fueron traspasados a matrices en formato Excel organizadas por folio. 


\section{Análisis de Datos}

En primer lugar, calculamos estadísticas descriptivas de las variables. Evaluamos nuestras hipótesis con modelos de regresión lineal (mínimos cuadrados ordinarios; en adelante MICO). Evaluamos el segundo grupo de hipótesis (2a y 2b) con regresiones lineales que incluyeron efectos de interacción entre la vivencia del desastre y los indicadores de confianza. Estandarizamos la variable dependiente en puntajes z. El escalamiento de las variables independientes centrales en términos de puntajes z es problemática, pues son dicotómicas. En consecuencia, no transformamos los predictores. La estandarización que utilizamos implica que los coeficientes de nuestras regresiones señalan las desviaciones estándares que puede cambiar la variable dependiente por el cambio de una unidad en la escala de respuesta de la variable independiente de interés. Junto a los modelos que recién mencionamos, realizamos tres análisis adicionales con el fin de evaluar la robustez de los resultados. Evaluamos problemas de multicolinealidad en base a factores de inflación de la varianza. Además, aplicamos pruebas de White para evaluar la presencia de heteroscedasticidad en las estimaciones. Finalmente, identificamos casos extremos (outliers) con la distancia de Cook.

Reestimamos las regresiones sin estos casos, con el fin de evaluar su influencia en los resultados. Todos los test estadísticos que presentamos son de dos colas. Realizamos los análisis con los programas estadísticos Stata 12.1 y R 3.3.2.

\section{Resultados}

Las estadísticas descriptivas de las variables se pueden ver en la Tabla 1.

Tabla 1

Estadisticas Descriptivas: Variables Dependientes e Independientes

\begin{tabular}{lcccc}
\hline \multicolumn{1}{c}{ Variable } & Media & $D E$ & Min & Max \\
\hline Apego al lugar (puntaje z) & 0,005 & 1,002 & $-3,884$ & 0,715 \\
Experiencia del desastre & 0,700 & 0,459 & 0 & 1 \\
Exposición individual al riesgo & 3,824 & 1,968 & 1 & 7 \\
Confianza en antiguos habitantes & 0,476 & 0,501 & 0 & 1 \\
Confianza en nuevos habitantes & 0,371 & 0,484 & 0 & 1 \\
Tiempo de residencia en Chaitén (años) & 21,824 & 16,810 & 0 & 71 \\
Arrendatario & 0,335 & 0,473 & 0 & 1 \\
Otra condición de propiedad & 0,382 & 0,487 & 0 & 1 \\
Sexo (mujer) & 0,565 & 0,497 & 0 & 1 \\
Estatus laboral & 0,194 & 0,397 & 0 & 1 \\
Educación & 0,324 & 0,469 & 0 & 1 \\
Ingreso: Q2 & 0,424 & 0,496 & 0 & 1 \\
Ingreso: Q3 & 0,159 & 0,367 & 0 & 1 \\
Ingreso: missing & 0,235 & 0,425 & 0 & 1 \\
\hline
\end{tabular}

Nota. Estatus laboral es una variable dicotómica con 1 para empleados y 0 para desempleados o inactivos; la variable educación es también una variable dicotómica con 1 para educación terciaria o más y 0 para educación secundaria o menor. $N=170$.

En la Tabla 2 mostramos los resultados de los modelos de regresión. El Modelo 1 permite evaluar la hipótesis 1. Tal como podemos ver en la Tabla 2, haber experimentado el desastre del 2008 está asociado directamente con el apego al lugar. La estimación del Modelo 1 sugiere que haber vivenciado el desastre está asociado con un aumento de 0,63 desviaciones estándares del apego al lugar.

El Modelo 2 nos permite evaluar las hipótesis 2 a y 2b. Las estimaciones se pueden ver en el Modelo 2 de la Tabla 2. Los resultados indican que existiría una tendencia a una interacción entre vivencia de la catástrofe y confianza en antiguos habitantes de Chaitén. Tal no es el caso para la interacción entre 
vivencia de la catástrofe y confianza en nuevos habitantes. En otras palabras, los resultados sugieren que la vivencia de la catástrofe solo moderaría levemente la asociación entre la confianza en los antiguos habitantes y el apego al lugar.

Tabla 2

Modelos de Regresión Lineal MICO: Apego a Chaitén

\begin{tabular}{|c|c|c|c|c|c|c|}
\hline & \multicolumn{3}{|c|}{ Modelo 1} & \multicolumn{3}{|c|}{ Modelo 2} \\
\hline & B & $t$ & $p$ & $B$ & $t$ & $p$ \\
\hline Experiencia del desastre & 0,632 & 3,415 & 0,001 & 0,949 & 4,281 & 0,000 \\
\hline Confianza en antiguos habitantes & & & & 0,634 & 2,213 & 0,028 \\
\hline Confianza en nuevos habitantes & & & & 0,288 & 1,013 & 0,313 \\
\hline Confianza en antiguos habitantes $\mathrm{x}$ experiencia del desastre & & & & $-0,645$ & $-1,890$ & 0,061 \\
\hline Confianza en nuevos habitantes $\mathrm{x}$ experiencia del desastre & & & & $-0,174$ & $-0,500$ & 0,618 \\
\hline \multicolumn{7}{|l|}{ Variables de control } \\
\hline Exposición individual al riesgo & $-0,038$ & $-1,132$ & 0,259 & $-0,033$ & $-1,013$ & 0,313 \\
\hline Tiempo de residencia en Chaitén & 0,011 & 2,061 & 0,041 & 0,011 & 1,956 & 0,052 \\
\hline \multicolumn{7}{|l|}{ Propiedad: referencia es propietario } \\
\hline Arrendatario & $-0,431$ & $-2,364$ & 0,019 & $-0,507$ & $-2,815$ & 0,006 \\
\hline Otra condición & 0,065 & 0,357 & 0,721 & 0,012 & 0,068 & 0,946 \\
\hline Mujer & $-0,048$ & $-0,338$ & 0,736 & $-0,033$ & $-0,240$ & 0,811 \\
\hline Estatus laboral $(1=$ empleado, $0=$ desempleado o inactivo $)$ & $-0,160$ & $-0,921$ & 0,359 & $-0,164$ & $-0,962$ & 0,337 \\
\hline Educación $(1=$ terciaria o mayor, 0 = secundaria o menor $)$ & 0,153 & 0,862 & 0,390 & 0,088 & 0,497 & 0,620 \\
\hline \multicolumn{7}{|l|}{ Ingreso mensual del hogar: referencia es Q1 } \\
\hline Ingreso: missing & $-0,354$ & $-1,675$ & 0,096 & $-0,346$ & $-1,668$ & 0,097 \\
\hline Ingreso: Q2-Q3 & $-0,149$ & $-0,763$ & 0,447 & $-0,181$ & $-0,942$ & 0,347 \\
\hline Ingreso: Q4 & $-0,793$ & $-2,964$ & 0,004 & $-0,844$ & $-3,219$ & 0,002 \\
\hline Intercepto & $-0,138$ & $-0,422$ & 0,674 & $-0,421$ & $-1,268$ & 0,207 \\
\hline$R^{2}$ & & 0,344 & & & 0,394 & \\
\hline$R^{2}$ ajustado & & 0,299 & & & 0,335 & \\
\hline$N$ & & 170 & & & 170 & \\
\hline
\end{tabular}

Con el fin de ilustrar las interacciones, en la Figura 1 mostramos los efectos marginales para las condiciones bajo análisis -el efecto marginal es el cambio en el valor (esperado) de la variable dependiente cuando la variable independiente cambia en una unidad, dejando el resto de las variables constantes-. Así, por ejemplo, la condición Sí en el Panel a representa el efecto marginal de confiar en los antiguos habitantes en el apego para los encuestados que vivían en Chaitén para la erupción de 2008. Pues bien, las estimaciones de la Figura 1 indican que el único intervalo de confianza que no topa con la línea roja, que denota un efecto de cero, se refiere a la condición representada por los encuestados que no experimentaron la erupción volcánica de 2008 y que dicen confiar en los antiguos habitantes (Panel a). Específicamente, las estimaciones indican que, para los que no vivieron el desastre, confiar en antiguos habitantes está asociado a un aumento de 0,63 desviaciones estándares del apego. En el mismo Panel a, dicho efecto disminuye a 0,01 desviaciones estándares para los que sí vivieron el desastre, no resultando significativo. En consecuencia, este resultado indica que este tipo de confianza está asociada directa y significativamente con apego al lugar solo para los que no vivenciaron el desastre. Además, podemos notar en el Panel b que los intervalos de confianza incluyen cero, lo que indica que no habría asociaciones entre confianza en nuevos habitantes y apego al lugar para las dos condiciones bajo análisis.

Finalmente, las pruebas de sensibilidad confirman que nuestros resultados son robustos. Primero, las estimaciones para las variables de control tiempo de residencia en Chaitén y arrendatario en la Tabla 2 confirman los resultados de la literatura (Lewicka, 2011), lo cual avala la calidad de nuestros datos. Segundo, estimaciones de factores de inflación de la varianza indican que este tipo de problema no es severo en nuestras estimaciones (ver Tabla A1 en el Anexo 2). Tercero, las pruebas de White indican que la hipótesis nula de homoscedasticidad no es rechazada ni para el modelo $1, \chi^{2}=69,089, p=0,279$, ni 
para el modelo $2, \chi^{2}=99,611, p=0,656$. Cuarto, análisis con distancias de Cook indican la presencia de casos extremos. En la Tabla 3 reportamos regresiones sin estos casos. Los análisis de robustez son consistentes con los resultados que ya hemos mostrado.

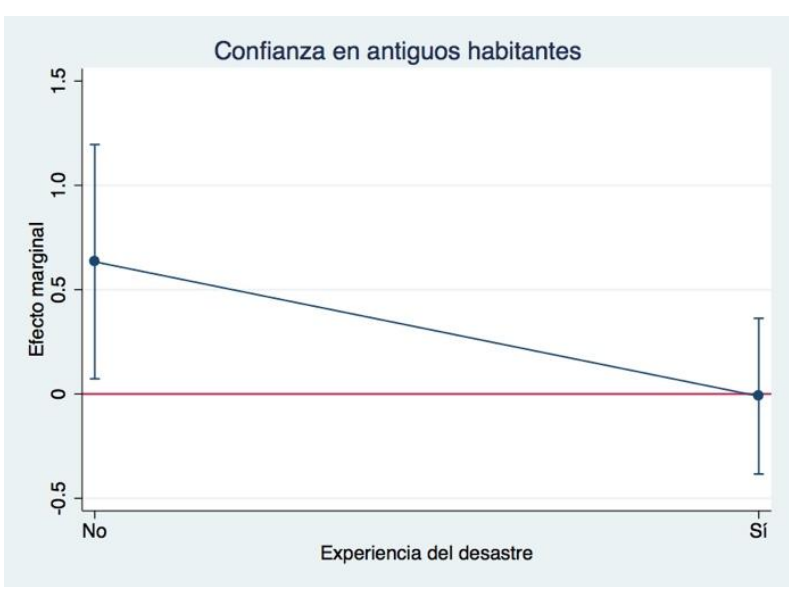

Panel a

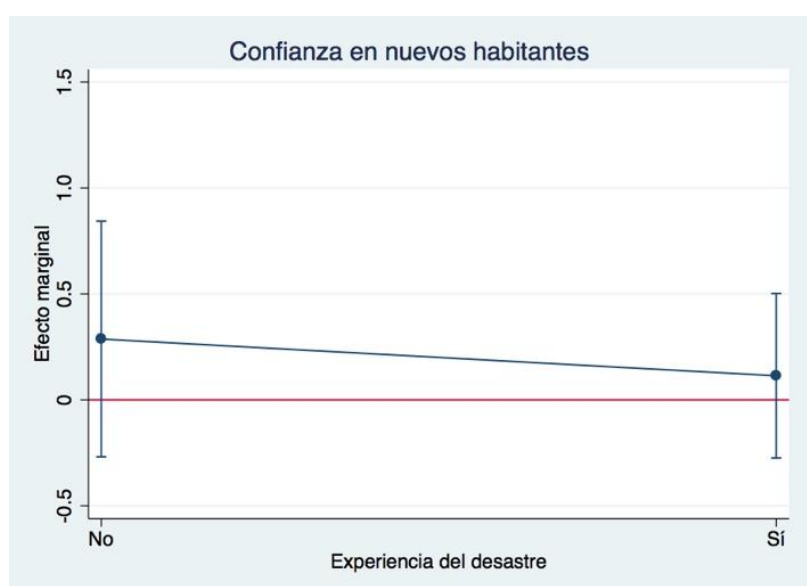

Panel b

Figura 1. Efectos de interacción: rol moderador de la experiencia del desastre en la asociación entre confianza interpersonal y apego al lugar. El tamaño muestral es de 170. Los puntos fueron estimados en base al Modelo 2 de la Tabla 2 y representan los efectos marginales para cada condición: No denota a personas que no vivían en Chaitén cuando sucedieron las erupciones de 2008 y Sí denota los que sí vivían en la ciudad para el desastre. Las líneas en torno a los puntos representan los intervalos de confianza al 95\% y la línea roja indica un efecto marginal igual a cero. Si los intervalos de confianza cruzan la línea roja, el efecto marginal no es significativo al $95 \%$.

Tabla 3

Modelos de Regresión Lineal MICO Sin Casos Extremos: Apego a Chaitén

\begin{tabular}{|c|c|c|c|c|c|c|}
\hline & \multicolumn{3}{|c|}{ Modelo 1} & \multicolumn{3}{|c|}{ Modelo 2} \\
\hline & $B$ & $t$ & $p$ & B & $t$ & $p$ \\
\hline Experiencia del desastre & 0,659 & 4,682 & $<0,001$ & 1,091 & 6,550 & $<0,001$ \\
\hline Confianza en antiguos habitantes & & & & 0,630 & 2,543 & 0,012 \\
\hline Confianza en nuevos habitantes & & & & 0,256 & 1,036 & 0,302 \\
\hline Confianza en antiguos habitantes $\mathrm{x}$ experiencia del desastre & & & & $-0,709$ & $-2,526$ & 0,013 \\
\hline Confianza en nuevos habitantes $\mathrm{x}$ experiencia del desastre & & & & $-0,139$ & $-0,488$ & 0,627 \\
\hline \multicolumn{7}{|l|}{ Variables de control } \\
\hline Exposición individual al riesgo & $-0,043$ & $-1,726$ & 0,087 & $-0,038$ & $-1,582$ & 0,116 \\
\hline Tiempo de residencia en Chaitén & 0,012 & 2,765 & 0,006 & 0,013 & 3,072 & 0,003 \\
\hline \multicolumn{7}{|l|}{ Propiedad: referencia es propietario } \\
\hline Arrendatario & $-0,407$ & $-2,967$ & 0,004 & $-0,430$ & $-3,209$ & 0,002 \\
\hline Otra condición & 0,128 & 0,940 & 0,349 & 0,066 & 0,488 & 0,626 \\
\hline Mujer & 0,043 & 0,400 & 0,690 & 0,028 & 0,260 & 0,796 \\
\hline Estatus laboral ( 1 = empleado, $0=$ desempleado o inactivo $)$ & $-0,026$ & $-0,193$ & 0,848 & $-0,145$ & $-1,106$ & 0,271 \\
\hline Educación $(1=$ terciaria o mayor, $0=$ secundaria o menor $)$ & 0,262 & 1,902 & 0,059 & 0,286 & 2,156 & 0,033 \\
\hline \multicolumn{7}{|l|}{ Ingreso mensual del hogar: referencia es Q1 } \\
\hline Ingreso: missing & $-0,224$ & $-1,412$ & 0,160 & $-0,378$ & $-2,459$ & 0,015 \\
\hline Ingreso: Q2-Q3 & $-0,126$ & $-0,875$ & 0,383 & $-0,228$ & $-1,625$ & 0,106 \\
\hline Ingreso: Q4 & $-0,638$ & $-3,125$ & 0,002 & $-0,722$ & $-3,676$ & $<0,001$ \\
\hline Intercepto & $-0,220$ & $-0,906$ & 0,366 & $-0,569$ & $-2,297$ & 0,023 \\
\hline$R^{2}$ & & 0,485 & & & 0,558 & \\
\hline$R^{2}$ ajustado & & 0,446 & & & 0,511 & \\
\hline$N$ & & 158 & & & 156 & \\
\hline
\end{tabular}




\section{Discusión}

Primero, confirmando nuestra hipótesis 1, los resultados indican que la experiencia directa de un desastre aumenta fuertemente el apego al lugar en la etapa post-desastre. En la literatura, Ruiz y Hernández (2014) estudian un fenómeno similar, aunque ellos se focalizan en los efectos de una amenaza natural en el apego al lugar luego de pasados unos cuantos meses desde la perturbación del ambiente, encontrando un efecto negativo. Por el contrario, nuestra investigación sugiere que un desastre también puede tener consecuencias positivas de largo plazo en el apego al lugar. Este resultado es consistente con estudios de las poblaciones desplazadas de Chaitén. En su comparación de los casos de Chaitén y Constitución post terremoto 2010, Berroeta et al. (2015) señalan que el apego al lugar físico es más fuerte en quienes regresan al lugar de origen que en aquellos desplazados que permanecen en el lugar de relocalización. Tomadas esta investigación y la nuestra en conjunto, podemos notar que, al parecer, la experiencia emocional negativa del desplazamiento reforzó el apego hacia el lugar de origen. Siguiendo evidencia en la literatura (Chamlee-Wright \& Storr, 2009), dicho reforzamiento tal vez fue producto de la idealización del lugar perdido. Al respecto, Low (1992) señala que el vínculo persona-lugar es activado retrospectivamente por la rememoración e idealización del lugar perdido, con la función de mantener la continuidad de sentido y la adaptación cultural. Una explicación alternativa de la asociación positiva de la vivencia del desastre con el apego al lugar se refiere al control que las personas retornadas fueron adquiriendo sobre el lugar habitado. El aumento del apego puede emerger como producto de la sensación saliente del control que pueden sentir aquellos que sobrellevaron el desastre y lograron recuperar y mantenerse en su lugar de apego. Nuestro estudio no presenta evidencia empírica que permita identificar el rol de cada uno de los mecanismos explicativos que vinculan la experiencia del desastre con el apego al lugar. La investigación futura debiera avanzar en esta línea.

Segundo, los análisis de las asociaciones entre confianza social y apego al lugar entregan evidencia parcial a favor de nuestras hipótesis. Respecto de la hipótesis $2 \mathrm{a}$, encontramos una asociación directa entre confianza en antiguos habitantes y apego al lugar solo para los encuestados que no vivían en Chaitén para la erupción volcánica de 2008. Respecto de los que sí experimentaron la catástrofe, no existe asociación. En relación con la hipótesis $2 \mathrm{~b}$, nuestros resultados también indican evidencia parcial a favor de nuestra hipótesis, en tanto sugieren que no hay asociación entre confianza en nuevos habitantes y apego al lugar para los que sí vivieron el desastre. Sorpresivamente, tampoco hay asociación entre estas dos últimas variables para los que no vivían en Chaitén en 2008. Tomados en conjunto, estos resultados indican que existe solo una de las cuatro asociaciones bajo análisis. Cabe destacar que no habrían asociaciones entre los dos tipos de confianza social que estudiamos y apego al lugar para las personas que vivieron la erupción volcánica.

En el contexto de la literatura sobre apego al lugar, ¿qué nos dicen substantivamente estos resultados sobre la asociación entre vínculos sociales y apego al lugar? Tal como ya señalamos, un número significativo de estudios reportan una asociación directa entre los vínculos sociales y apego al lugar. Además, en términos teóricos, los lazos sociales examinados en general se refieren a círculos sociales formados por amigos, vecinos y familiares (Lewicka, 2011; Mihayloy \& Perkins, 2014). Si consideramos ambos patrones de la literatura bajo la lupa de nuestros resultados, emergen dos mensajes substantivos de nuestra investigación. Primero, nuestros resultados muestran que pueden existir ciertas condiciones en donde la asociación directa no estaría emergiendo. Particularmente, nuestro estudio muestra que la vivencia de una fuerte disrupción del ambiente puede disolver la asociación entre ciertos vínculos sociales y apego al lugar. Segundo, nuestros resultados sobre confianza social también sugieren la necesidad de avanzar en el estudio de los mecanismos explicativos de estos y considerar distintos tipos de relaciones intergrupales. Al respecto, entendiendo que el desplazamiento de la población de Chaitén implicó la disgregación de la comunidad en grupos familiares nucleares, la seguridad de las personas respecto de su lugar de origen se puede haber centrado en estos vínculos más que en toda la comunidad de Chaitén pre-desastre. Como investigación futura, esto sugiere que se podría profundizar en tipos particulares de relaciones intergrupales a través del examen de tipos de confianza particularizada más específicos que los que investigamos, por ejemplo, estudiar directamente confianza en familiares o amigos, más que usar la categoría antiguos habitantes.

Nuestra investigación tiene limitantes que indican áreas adicionales de interés para la investigación futura. En nuestro estudio, nos enfocamos en un modelo bidimensional de apego al lugar que no considera los vínculos sociales como dimensión de este. Dicha decisión nos permitió trasladar el foco desde qué se mide a por qué emerge el vínculo persona-lugar. Futura investigación podría evaluar el instrumento que 
utilizamos en otros contextos, de modo de saber si el comportamiento de este en nuestro estudio —un solo factor - es algo propio del caso que hemos estudiado o puede ser generalizado a otras circunstancias, particularmente a contextos de disrupciones del ambiente. Investigación cualitativa también sería de gran ayuda para entender cómo el proceso de retorno se va traduciendo en un aumento de la sensación de control sobre el lugar.

Por último, cabe señalar algunas implicaciones prácticas. Un mayor conocimiento sobre el apego al lugar en contextos de desastres puede favorecer la forma con que se aborda tanto la reconstrucción como la mitigación frente a nuevas amenazas. Comprender que la experiencia del desastre aumenta el apego al lugar debe considerarse para los procesos de fortalecimiento de la identidad colectiva. Asimismo, y en línea con la evidencia existente (Chamlee-Wright \& Storr, 2009), la identificación de los grupos más apegados a un lugar en riesgo permitiría predecir la vulnerabilidad asociada a la resistencia frente a nuevas evacuaciones y la motivación a retornar.

\section{Referencias}

Abascal, M. \& Baldassarri, D. (2015). Love thy neighbor? Ethnoracial diversity and trust reexamined. American Journal of Sociology, 121, 722-782. https://doi.org/10.1086/683144

Anton, C. E. \& Lawrence, C. (2016). The relationship between place attachment, the theory of planned behaviour and residents' response to place change. Journal of Environmental Psychology, 47, 145-154. https://doi.org/10.1016/j.jenvp.2016.05.010

Arteaga, C. \& Ugarte, A. M. (2015). Identidades en emergencia: la otra cara de la reconstrucción. El caso de Chaitén. Magallania, 43(3), 107-123. https://doi.org/10.4067/S0718-22442015000300009

Berezin, A. D. (2015). Chaitén: una historia en el lugar. Magallania, 43(3), 91-106. https://doi.org/10.4067/S0718-22442015000300008

Berroeta, H., Ramoneda, A. \& Opazo, L. (2015). Sentido de comunidad, participación y apego al lugar en comunidades desplazadas y no desplazadas post desastres: Chaitén y Constitución. Universitas Psychologica, 14, 1221-1233. https://doi.org/10.11144/Javeriana.up14-4.scpa

Berroeta, H., Ramoneda, A., Rodriguez, V., Di Masso, A. \& Vidal, T. (2015). Apego de lugar, identidad de lugar, sentido de comunidad y participación cívica en personas desplazadas de la ciudad de Chaitén. Magallania, 43(3), 51-63. https://doi.org/10.4067/S071822442015000300005

Bronfman, N. C., Cisternas, P. C., López-Vázquez, E. \& Cifuentes, L. A. (2016). Trust and risk perception of natural hazards: Implications for risk preparedness in Chile. Natural Hazards, 81, 307-327. https://doi.org/10.1007/s11069-015-2080-4

Chamlee-Wright, E. \& Storr, V. H. (2009). "There's no place like New Orleans": Sense of place and community recovery in the ninth ward after Hurricane Katrina. Journal of Urban Affairs, 31, 615-634. https://doi.org/10.1111/j.1467-9906.2009.00479.x

Chile, Instituto Nacional de Estadísticas (2018). Resultados Censo de Población y Vivienda 2017. Santiago, Chile: Autor.

Chile, Ministerio del Interior y Seguridad Pública (2014). Diagnóstico estado de la reconstrucción erupción Volcán Chaitén, 2 de mayo de 2008. Santiago, Chile: Autor.

Collins, T. W. (2009). Influences on wildfire hazard exposure in Arizona's high country. Society \& Natural Resources, $22,211-229$. https://doi.org/10.1080/08941920801905336

Dallago, L., Perkins, D. D., Santinello, M., Boyce, W., Molcho, M. \& Morgan, A. (2009). Adolescent place attachment, social capital, and perceived safety: A comparison of 13 countries. American Journal of Community Psychology, 44, 148-160. https://doi.org/10.1007/s10464-009-9250-z

De Dominicis, S., Fornara, F., Cancellieri, U. G., Twigger-Ross, C. \& Bonaiuto, M. (2015). We are at risk, and so what? Place attachment, environmental risk perceptions and preventive coping behaviours. Journal of Environmental Psychology, 43, 66-78. https://doi.org/10.1016/j.jenvp.2015.05.010

Delhey, J., Newton, K. \& Welzel, C. (2011). How general is trust in "most people"? Solving the radius of trust problem. American Sociological Review, 76, 786-807. https://doi.org/10.1177/0003122411420817

Devine-Wright, P. (2011). Place attachment and public acceptance of renewable energy: A tidal energy case study. Journal of Environmental Psychology, 31, 336-343. https://doi.org/10.1016/j.jenvp.2011.07.001

Ermisch, J. \& Gambetta, D. (2010). Do strong family ties inhibit trust? Journal of Economic Behavior \& Organization, 75, 365-376. https://doi.org/10.1016/j.jebo.2010.05.007

Espinoza, A. E., Espinoza, C. E. \& Fuentes, A. A. (2015). Retornando a Chaitén: diagnóstico participativo de una comunidad educativa desplazada por un desastre socionatural. Magallania, 43(3), 65-76. https://doi.org/10.4067/S0718-22442015000300006

Fátima, B. (2013). Impact of place attachment on risk perception: Exploring the multidimensionality of risk and its magnitude. Estudios de Psicología, 34, 323-329. https://doi.org/10.1174/021093913808349253

Freitag, M. \& Bauer, P. C. (2013). Testing for measurement equivalence in surveys: Dimensions of social trust across cultural contexts. Public Opinion Quarterly, 77(S1), 24-44. https://doi.org/10.1093/poq/nfs064

Hernández, B., Hidalgo, M. C. \& Ruiz, C. (2014). Theoretical and methodological aspects of research on place attachment. En L. C. Manzo \& P. Devine-Wright (Eds.), Place attachment: Advances in theory, methods and applications (pp. 125-138). New York, NY: Routledge.

Hidalgo, M. C. \& Hernández, B. (2001). Place attachment: Conceptual and empirical questions. Journal of Environmental Psychology, 21, 273-281. https://doi.org/10.1006/jevp.2001.0221

Jorgensen, B. S. \& Stedman, R. C. (2001). Sense of place as an attitude: Lakeshore owners attitudes toward their properties. Journal of Environmental Psychology, 21, 233-248. https://doi.org/10.1006/jevp.2001.0226

Lara, L. E. \& Calderón, R. (2015). Peligro y riesgo específico asociado al volcán Chaitén: perspectiva geológica de la vulnerabilidad en el entorno de un volcán activo. Magallania, 43(3), 27-35. https://doi.org/10.4067/S0718-22442015000300003

Lewicka, M. (2005). Ways to make people active: The role of place attachment, cultural capital, and neighborhood ties. Journal of Environmental Psychology, 25, 381-395. https://doi.org/10.1016/j.jenvp.2005.10.004

Lewicka, M. (2010). What makes neighborhood different from home and city? Effects of place scale on place attachment. Journal of Environmental Psychology, 30, 35-51. https://doi.org/10.1016/j.jenvp.2009.05.004 
Lewicka, M. (2011). Place attachment: How far have we come in the last 40 years? Journal of Environmental Psychology, 31, 207-230. https://doi.org/10.1016/j.jenvp.2010.10.001

Low, S. M. (1992). Symbolic ties that bind: Place attachment in the plaza. En I. Altman \& S. M. Low (Eds.), Place attachment (pp. 165185). New York, NY: Plenum Press.

Major, J. J. \& Lara, L. E. (2013). Overview of Chaitén Volcano, Chile, and its 2008-2009 eruption. Andean Geology, 40, 196-215. https://doi.org/10.5027/andgeoV40n2-a01

Mandujano, F. \& Rodríguez, J. C. (2016). La catástrofe del 2008 en la provincia de Palena: reflexiones sobre sus particularidades e impacto en la Patagonia Occidental. Magallania, 44(2), 69-85. https://doi.org/10.4067/S0718-22442016000200004

Manzo, L. C. \& Devine-Wright, P. (Eds.) (2014). Place attachment: Advances in theory, methods and applications. New York, NY: Routledge.

Mihayloy, N. \& Perkins, D. D. (2014). Community place attachment and its role in social capital development. En L. C. Manzo \& P. Devine-Wright (Eds.), Place attachment: Advances in theory, methods and applications (61-74). New York, NY: Routledge.

Mishra, S., Mazumdar, S. \& Suar, D. (2010). Place attachment and flood preparedness. Journal of Environmental Psychology, 30, 187197. https://doi.org/10.1016/j.jenvp.2009.11.005

Pierson, T. C., Major, J. J., Amigo, Á. \& Moreno, H. (2013). Acute sedimentation response to rainfall following the explosive phase of the 2008-2009 eruption of Chaitén Volcano, Chile. Bulletin of Volcanology, 75, Article 723. https://doi.org/10.1007/s00445-013-0723-4

Proshansky, H. M., Fabian, A. K. \& Kaminoff, R. (1983). Place-identity: Physical world socialization of the self. Journal of Environmental Psychology, 3, 57-83. https://doi.org/10.1016/S0272-4944(83)80021-8

Putnam, R. D. (1995). Bowling alone: America's declining social capital. Journal of Democracy, 6(1), 65-78. https://doi.org/10.1353/jod.1995.0002

Raymond, C. M., Brown, G. \& Weber, D. (2010). The measurement of place attachment: Personal, community, and environmental connections. Journal of Environmental Psychology, 30, 422-434. https://doi.org/10.1016/j.jenvp.2010.08.002

Ruiz, C. \& Hernández, B. (2014). Emotions and coping strategies during an episode of volcanic activity and their relations to place attachment. Journal of Environmental Psychology, 38, 279-287. https://doi.org/10.1016/j.jenvp.2014.03.008

Russell, J. A. \& Ward, L. M. (1982). Environmental psychology. Annual Review of Psychology, 33, 651-688. https://doi.org/10.1146/annurev.ps.33.020182.003251

Scannell, L. \& Gifford, R. (2010). Defining place attachment: A tripartite organizing framework. Journal of Environmental Psychology, 30, 1-10. https://doi.org/10.1016/j.jenvp.2009.09.006

Slovic, P. (2000). Perception of risk. En P. Slovic (Ed.), The perception of risk (pp. 220-231). London, Reino Unido: Earthscan.

Stokols, D. \& Shumaker, S. A. (1981). People in places: A transactional view of settings. En J. H. Harvey (Ed.), Cognition, social behavior, and the environment (pp. 441-488). Hillsdale, NJ: Lawrence Erlbaum.

Tierney, K. (2014). The social roots of risk: Producing disasters, promoting resilience. Stanford, CA: Stanford University Press.

Trentelman, C. K. (2009). Place attachment and community attachment: A primer grounded in the lived experience of a community sociologist. Society \& Natural Resources, 22, 191-210. https://doi.org/10.1080/08941920802191712

Ugarte Caviedes, A. M. \& Salgado Vargas, M. A. (2014). Sujetos en emergencia: acciones colectivas de resistencia y enfrentamiento del riesgo ante desastres; el caso de Chaitén, Chile. Revista INVI, 29(80), 143-168. https://doi.org/10.4067/S0718-83582014000100006

Williams, D. R. (2014). "Beyond the commodity metaphor", revisited: Some methodological reflections on place attachment research. En L. C. Manzo \& P. Devine-Wright (Eds.), Place attachment: Advances in theory, methods and applications (pp. 89-99). New York, NY: Routledge.

Williams, D. R. \& Roggenbuck, J. W. (1989, Octubre). Measuring place attachment: Some preliminary results. Ponencia presentada en el NRPA Symposium on Leisure Research, San Antonio, TX, Estados Unidos.

Williams, D. R. \& Vaske, J. J. (2003). The measurement of place attachment: Validity and generalizability of a psychometric approach. Forest Science, 49, 830-840. https://doi.org/10.1093/forestscience/49.6.830

Yamagishi, T., Cook, K. S. \& Watabe, M. (1998). Uncertainty, trust, and commitment formation in the United States and Japan. American Journal of Sociology, 104, 165-194. https://doi.org/10.1086/210005 


\section{Anexo 1}

\section{Batería de Apego al Lugar}

\begin{tabular}{|c|c|c|c|c|c|c|}
\hline & & $\begin{array}{l}\text { Totalmente } \\
\text { en } \\
\text { desacuerdo }\end{array}$ & $\begin{array}{c}\text { En } \\
\text { desacuerdo }\end{array}$ & $\begin{array}{l}\text { Ni de } \\
\text { acuerdo } \\
\text { Ni en } \\
\text { desacuerdo }\end{array}$ & De acuerdo & $\begin{array}{l}\text { Totalmente } \\
\text { de acuerdo }\end{array}$ \\
\hline 1. & Usted siente que CHAITÉN es parte de usted & 1. & 2. & 3. & 4. & 5. \\
\hline 2. & $\begin{array}{l}\text { CHAITÉN es el mejor lugar para hacer lo que } \\
\text { le gusta hacer a usted }\end{array}$ & 1. & 2. & 3. & 4. & 5. \\
\hline 3. & CHAITÉN es muy especial para usted & 1. & 2. & 3. & 4. & 5. \\
\hline 4. & $\begin{array}{l}\text { Ningún lugar puede compararse con } \\
\text { CHAITÉN }\end{array}$ & 1. & 2. & 3. & 4. & 5. \\
\hline 5. & $\begin{array}{l}\text { Usted se identifica fuertemente con } \\
\text { CHAITÉN }\end{array}$ & 1. & 2. & 3. & 4. & 5. \\
\hline 6. & $\begin{array}{l}\text { Usted recibe más satisfacción estando en } \\
\text { CHAITÉN que en cualquier otro lugar }\end{array}$ & 1. & 2. & 3. & 4. & 5. \\
\hline 7. & Usted está muy apegado/a a CHAITÉN & 1. & 2. & 3. & 4. & 5. \\
\hline 8. & $\begin{array}{l}\text { Hacer lo que hace en CHAITÉN es más } \\
\text { importante para usted que hacerlo en } \\
\text { cualquier otro lugar }\end{array}$ & 1. & 2. & 3. & 4. & 5. \\
\hline 9. & $\begin{array}{l}\text { Estar en CHAITÉN dice mucho sobre quién es } \\
\text { usted }\end{array}$ & 1. & 2. & 3. & 4. & 5. \\
\hline 10. & $\begin{array}{l}\text { Usted no cambiaría CHAITÉN por ningún } \\
\text { otro lugar para hacer las cosas que hace } \\
\text { ahí/aquí }\end{array}$ & 1. & 2. & 3. & 4. & 5. \\
\hline 11. & CHAITÉN significa mucho para usted & 1. & 2. & 3. & 4. & 5. \\
\hline 12. & $\begin{array}{l}\text { Las cosas que hace en CHAITÉN las } \\
\text { disfrutaría igual haciéndolas en un lugar } \\
\text { parecido }\end{array}$ & 1. & 2. & 3. & 4. & 5. \\
\hline
\end{tabular}

Nota. Los factores se evalúan por Identidad: 1, 3, 5, 7, 9, 11; Dependencia: 2, 4, 6, 8, 10, 12. 


\section{Anexo 2}

\section{Análisis Psicométrico del Instrumento}

Realizamos análisis factoriales exploratorios (AFE), tras considerar que los datos fueran adecuados, según la medida de adecuación muestral de Kaiser-Meyer-Olkin, KMO = 0,940. Realizamos la extracción de factores en base al método de componentes principales y evaluamos el número de factores a través del scree test. Tal como se puede ver en la Figura A1, el resultado del AFE sugirió gráficamente una estructura de un factor, cuyo valor propio es 8,528 y tiene una varianza explicada de $78 \%$. Las cargas factoriales de este factor varían entre 0,8229 y 0,938 . El método de componentes principales supone uniquidades iguales a cero. En nuestros análisis, las uniquidades varían de 0,121 a 0,322. Para evaluar la robustez de los resultados y relajar este supuesto, también estimamos AFE con el método de máxima verosilimitud, el cual no modificó substantivamente los resultados. Dado que extrajimos solo un factor, no aplicamos métodos de rotación. Sin embargo, la aplicación de estos no modifica los resultados del AFE.

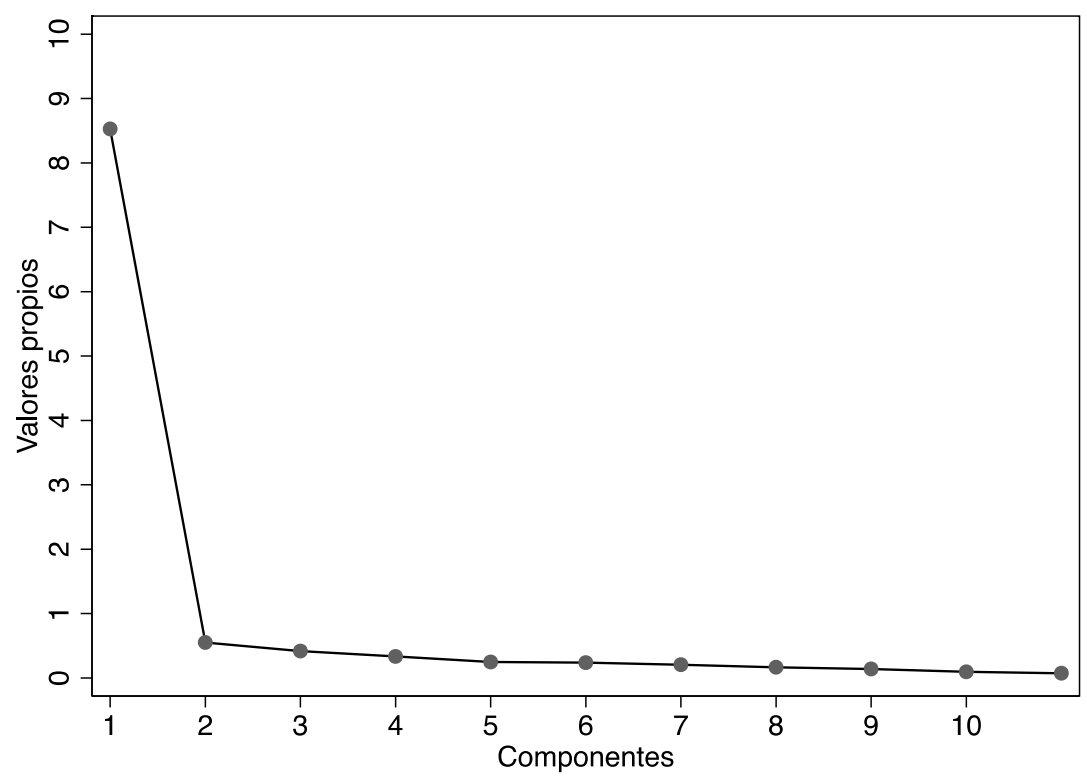

Figura A1. Solución gráfica del AFE con número de factores posibles. 
Tabla A1

Factores de Inflación de la Varianza. Estimaciones Realizadas con el Modelo 1 de la Tabla 2

\begin{tabular}{lc}
\hline \multicolumn{1}{c}{ Variable } & Factores \\
Experiencia del desastre & 1,734 \\
Exposición individual al riesgo & 1,030 \\
Tiempo de residencia en Chaitén (años) & 2,022 \\
Arrendatario & 1,791 \\
Otra condición de propiedad & 1,901 \\
Sexo (mujer) & 1,189 \\
Estatus laboral & 1,140 \\
Educación & 1,671 \\
Ingreso: Q2 & 2,254 \\
Ingreso: Q3 & 2,312 \\
Ingreso: missing & 1,943 \\
\hline Nota. Factores de inflación de la varianza mayores que 10 indican \\
problemas de multicolinealidad.
\end{tabular}

Fecha de recepción: Noviembre de 2017.

Fecha de aceptación: Mayo de 2019. 